\title{
Effect of High-Energy Vibrating Ball Milling in the Reduction of the Crystallite Size of $\mathrm{TiO}_{2}$ Particles
}

\author{
Ganbat Batdemberel, Dugerjav Otgonbayar, Gonchigsuren Munkhsaikhan \\ Department of Physics, School of Applied Sciences, Mongolian University of Science and Technology, Ulaanbaatar, Mongolia \\ Email: gdembee@must.edu.mn
}

How to cite this paper: Batdemberel, G., Otgonbayar, D. and Munkhsaikhan, G. (2021) Effect of High-Energy Vibrating Ball Milling in the Reduction of the Crystallite Size of $\mathrm{TiO}_{2}$ Particles. Journal of Materials Science and Chemical Engineering, 9, 7-14. https://doi.org/10.4236/msce.2021.911002

Received: September 3, 2021

Accepted: November 14, 2021

Published: November 17, 2021

Copyright $\odot 2021$ by author(s) and Scientific Research Publishing Inc. This work is licensed under the Creative Commons Attribution International License (CC BY 4.0).

http://creativecommons.org/licenses/by/4.0/

\begin{abstract}
In this work, $\mathrm{TiO}_{2}$ powders were prepared by high energy vibrating ball milling. X-ray diffraction (XRD), Scanning electron microscopy (SEM) and Photon cross correlation spectroscopy (PCCS with Nanophox) were used to determine the crystallite size of anatase $\mathrm{TiO}_{2}$. Depending on the grinding conditions (short grinding time, ball diameter, stainless steel ball and grinding powder ratio), the crystallite size decreased from $34 \mathrm{~nm}$ to $8 \mathrm{~nm}$. The average diameter of a $\mathrm{TiO}_{2}$ particle with $8 \mathrm{~nm}$ crystals was $\sim 221 \mathrm{~nm}$. No structural phase transition was observed during milling.
\end{abstract}

\section{Keywords}

X-Ray Diffraction, Scanning Electron Microscopy, Anatase, Nanoparticle

\section{Introduction}

The $\mathrm{TiO}_{2}$ compound has two main modifications, anatase and rutile, and at high temperatures the anatase phase is converted to the rutile phase. $\mathrm{TiO}_{2}$ powder is used to produce white paint. Nanostructured $\mathrm{TiO}_{2}$ is widely used in photocatalysis, electronics, energy and environment [1] [2] [3]. In recent years, much research has been conducted on the use of nanostructured rutile $\mathrm{TiO}_{2}$ as a phase transition material for latent heat energy storage [4] [5] [6] [7]. $\mathrm{TiO}_{2}$ has been used to improve some parameters of phosphate glass for solid state batteries [8] [9]. Long-term (up to $100 \mathrm{~h}$ ) grinding of anatase $\mathrm{TiO}_{2}$ in a high-energy vibrating ball mill has been shown to lead to structural phase changes, but not to an amorphous process [10]. In the mechanochemical synthesis of $\mathrm{TiO}_{2}$ nanoparticles, it has been observed that the anatase phase transforms into the rutile phase with increasing temperature [11]. 
In this work, we aim to reduce the crystal size of anatase-type $\mathrm{TiO}_{2}$ powder using a high-energy ball mill for the study of heat storage materials.

\section{Experimental}

1) Milling process: High purity (99.8\%) anatase type $\mathrm{TiO}_{2}$ (IV) powder was used in the present study. The $10 \mathrm{~g}$ powder sample was placed in a dry $80 \mathrm{ml}$ steel cylindrical container with a high-purity steel ball in a 1200 $\mathrm{rpm} / \mathrm{min}$. Table-top high-energy vibrating ball mill (Across International, Material Processing Equipment-ISO 9001:2015) manufactured in the United States. To avoid the agglomeration process of particle and device overheating, it was milled for 5 minutes and cooled for $1 \mathrm{~h}$ at $-35^{\circ} \mathrm{C}$ temperature. This milling procedure is an advanced part of our work. Milling was carried out between 15 minutes and 8 hours and 25 minutes. The milling process of $\mathrm{TiO}_{2}$ powder is summarized in Table 1.

Eight large steel balls with a diameter of $1 \mathrm{~mm}$ were used for 15 and $30 \mathrm{mi}-$ nutes of grinding. The total weight of these balls was $65.71 \mathrm{~g}$. At this time, the mass ratio between the powder sample and the steel ball was 1:6. 17 small steel balls with a diameter of $0.5 \mathrm{~mm}$ and a total weight of $58.05 \mathrm{~g}$ were used during the 1- and 3-hour grinding periods. The mass ratio between the powder sample and the steel ball was 1:5. Also, 36 small steel balls with a diameter of $0.3 \mathrm{~mm}$ were ground for 5, 6, and 7 hours. The total weight of these balls was $34.52 \mathrm{~g}$. In this case, the mass ratio between the powder sample and the steel ball was 1:3. Then, a mixture of balls with different diameters ( 2 steel balls with a diameter of $1 \mathrm{~mm}, 4$ steel balls with a diameter of $0.8 \mathrm{~mm}, 3$ steel balls with a diameter of 0.5 $\mathrm{mm}, 7$ steel balls with a diameter of $0.3 \mathrm{~mm}$ ) was used during the milling period of 8 hours and 25 minutes. Their total weight was $41.9 \mathrm{~g}$ and the mass ratio between the powder sample and the steel ball was 1:4. Figure 1 shows the grinding process and the tools used in the study.

Table 1. Number, diameter, powder/balls mass ratio, and total weight of steel balls at different meals.

\begin{tabular}{ccccc}
\hline Milling time & $\begin{array}{c}\text { Number of } \\
\text { steel balls }\end{array}$ & $\begin{array}{c}\text { Diameter of steel } \\
\text { balls, mm }\end{array}$ & $\begin{array}{c}\text { Mass ratio of } \\
\text { powder/balls }\end{array}$ & $\begin{array}{c}\text { The total } \\
\text { weight of the } \\
\text { balls, } \mathrm{g}\end{array}$ \\
\hline $\begin{array}{c}15 \mathrm{~min} \\
30 \mathrm{~min}\end{array}$ & 8 & 1 & $1: 6$ & 65.71 \\
$1 \mathrm{~h}$ & 17 & 1 & $1: 6$ & 65.71 \\
$3 \mathrm{~h}$ & 17 & 0.5 & $1: 5$ & 58.05 \\
$5 \mathrm{~h}$ & 36 & 0.5 & $1: 5$ & 58.05 \\
$6 \mathrm{~h}$ & 36 & 0.3 & $1: 3$ & 34.52 \\
$7 \mathrm{~h}$ & 36 & 0.3 & $1: 3$ & 34.52 \\
$8 \mathrm{~h}$ and 25 & $(2+4+3+7)$ & $1+0.8+0.5+0.3$ & $1: 4$ & 34.52 \\
min & & & & 41.90 \\
\hline
\end{tabular}




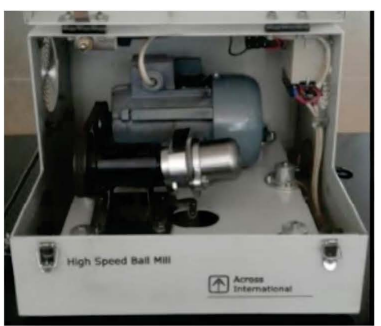

(a)

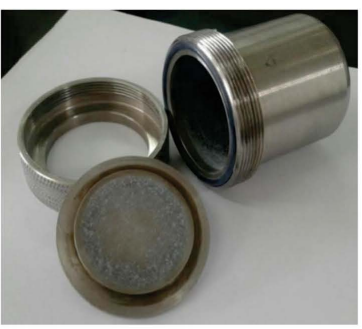

(b)

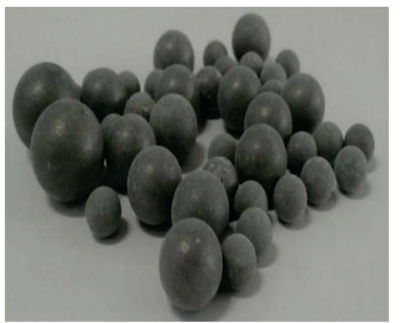

(c)

Figure 1. Tools and equipment used in the grinding process: (a) High energy vibrating ball mill; (b) Steel container for powder sample; (c) Stainless steel balls with different diameters.

The grinding method we used reduced the crystallite size in a short time, and this grinding method is slightly different from the grinding methods used by other reseachers.

2) Scanning electron microscopy (SEM): The study samples were measured by scanning electron microscope with EDX. The measurement results are shown in Figure 2 and Figure 3.

In Figure 2, large particles with a size of $5 \mu \mathrm{m}$ can be seen. Due to the low resolution of SEM, the shape and size of the particles could not be observed well. In the section marked with the letter A in Figure 2, the analysis only detected the elements $\mathrm{Ti}$.

The elemental analysis did not reveal any elements other than only $\mathrm{Ti}$.

3) $X$-ray diffraction study $(X R D)$ : XRD measurements were performed at ambient conditions using an X-ray powder diffractometer (Enraf Nonius Delft). A step size of $0.02^{\circ}$, an integration time of $2 \mathrm{~s}$ per step and a scan range of $13^{\circ}$ to $70^{\circ}$ were used. The program "FullProf. Suite" [12] was used to calculate peak position, peak width and peak intensity in the X-ray patterns. The X-ray diffraction spectrum of the non-milled primary sample is shown in Figure 4.

$\mathrm{X}$-ray phase analysis revealed that the primary sample $\mathrm{TiO}_{2}$ is a tetragonal symmetric anatase-type titanium oxide $\left(\mathrm{TiO}_{2}\right.$ (IV)) with space group I41/amd. Figure 3 shows the Miller indices (hkl) corresponding to the diffraction peaks of the anatase type of $\mathrm{TiO}_{2}$, with the numbers in parentheses. This shows that the diffraction peak with the highest intensity is the Miller index (101). The extension of the diffraction line analysis was performed on an actual peak profile with an index (101). No phase changes and no amorphization were observed in the $\mathrm{X}$-ray pattern during the milling period of up to 8 hours. However, in [8], two structural phase transitions (metastable phase $\mathrm{TiO}_{2}$ (II) and high pressure $\mathrm{TiO}_{2}$ (B)) were observed during milling of anatase-type $\mathrm{TiO}_{2}$ powder for up to 100 hours. Figure 5 compares the $\mathrm{X}$-ray patterns of $\mathrm{TiO}_{2}$ samples measured at different times using an X-ray diffractometer. As can be seen in Figure 5, the intensity of the diffraction peaks decreases and the width of the peaks increases with increasing grinding time.

The following Scherrer's equation was used to determine the crystallite size of the samples: 


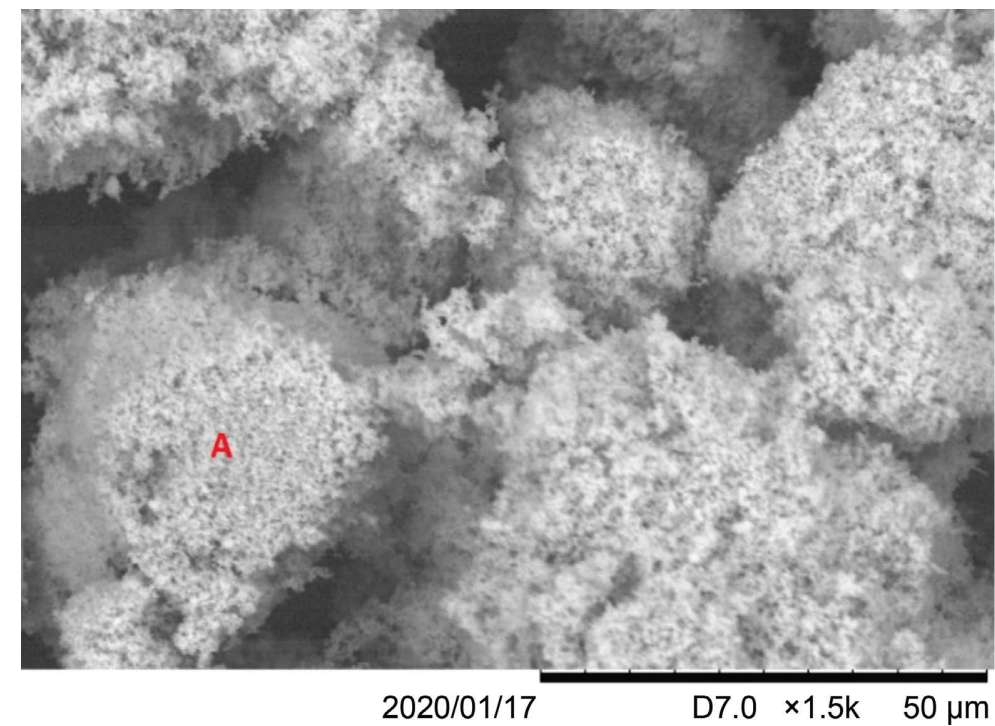

Figure 2. Micrograph of the original $\mathrm{TiO}_{2}$ powder taken by Scanning Electron Microscopy (SEM) (Image magnified up to $50 \mu \mathrm{m}$ ).

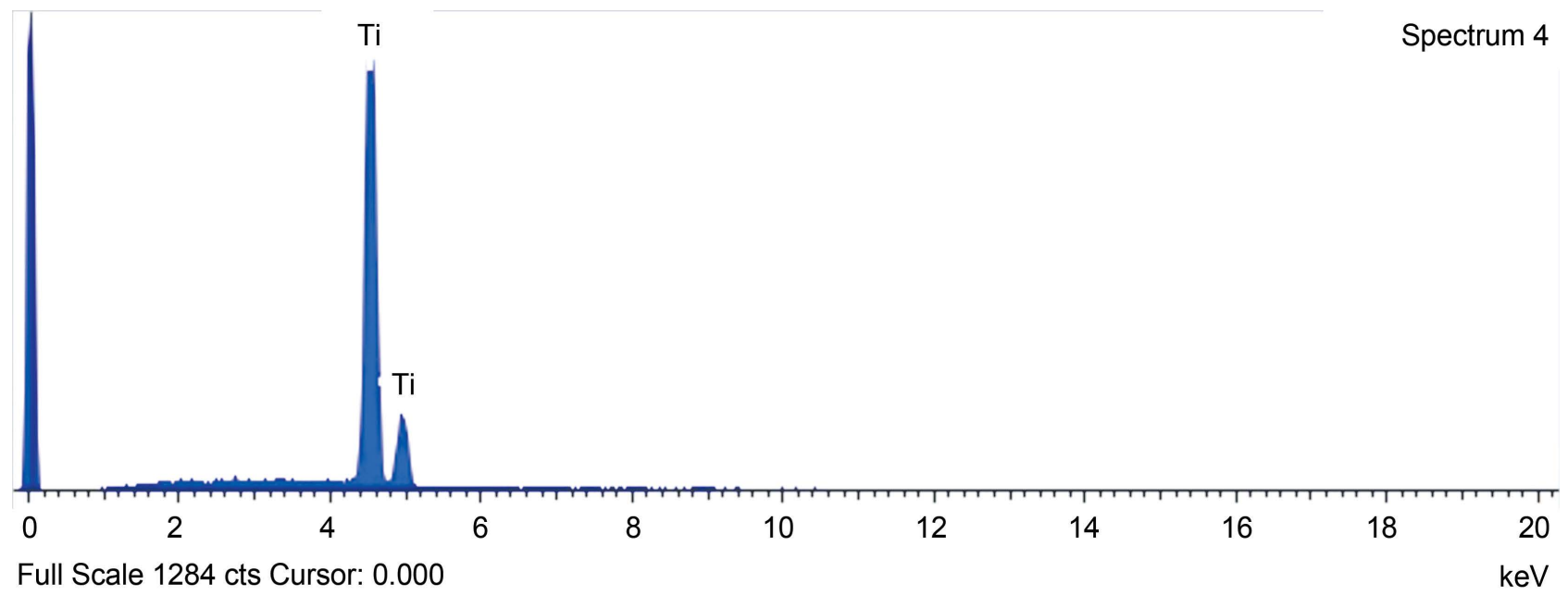

Figure 3. Results of elemental analysis performed on individual large particles (A).

$$
D_{c}=\frac{K \cdot \lambda}{\cos \theta \cdot \Delta B(2 \theta)}
$$

where $\lambda$ is the wavelength of the X-rays $\left(\mathrm{Cu} / \mathrm{K}_{\alpha}=0.154 \mathrm{~nm}\right), \Delta B(2 \theta)$ is the full width corresponding to half the height of the highest intensity peak in the X-ray pattern, $\theta$ is the Bragg angle. The factor $K$ depends on the shape of the particle and is 0.94 in the case of spherical particles.

The crystallite sizes of $\mathrm{TiO}_{2}$ were determined using Equation (1). The values of the full width at half height of the highest peak on the X-ray pattern of the samples (see Figure 5) were used. The results are shown in Table 2.

As can be seen from Table 2, the corresponding crystallite size in the original sample was fixed at $34 \mathrm{~nm}$. After grinding for 15 to 30 minutes, the crystallite size was reduced to $27 \mathrm{~nm}$. However, during 1 hour grinding, it increased 


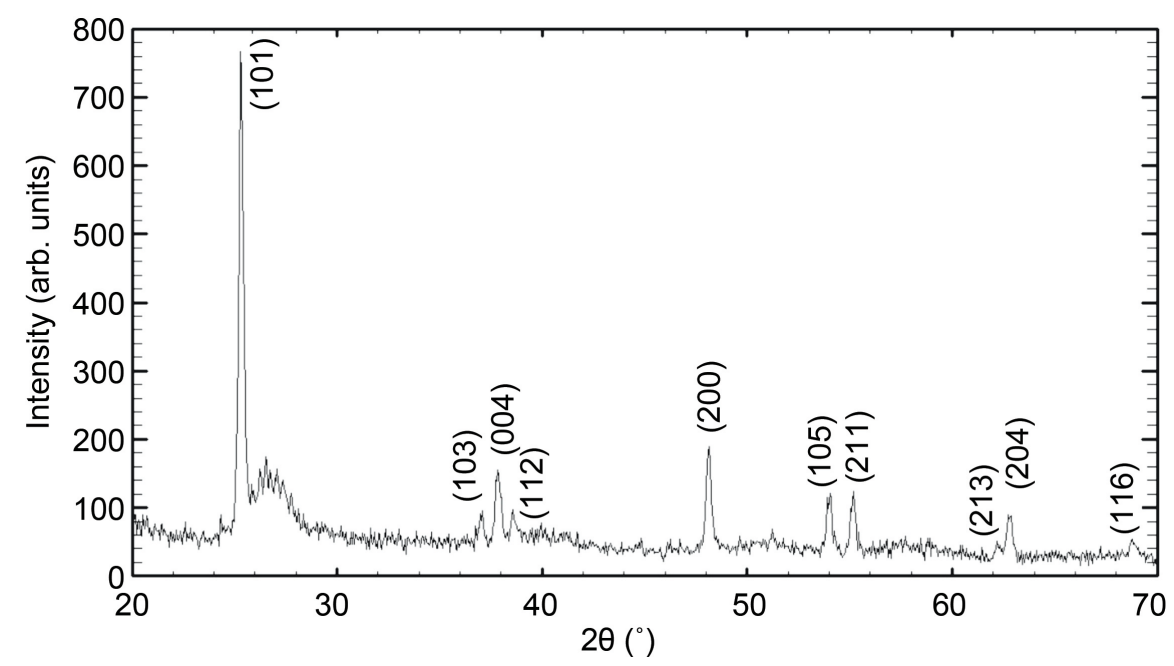

Figure 4. X-ray diffraction pattern of the (unmilled) primary sample $\mathrm{TiO}_{2}$.

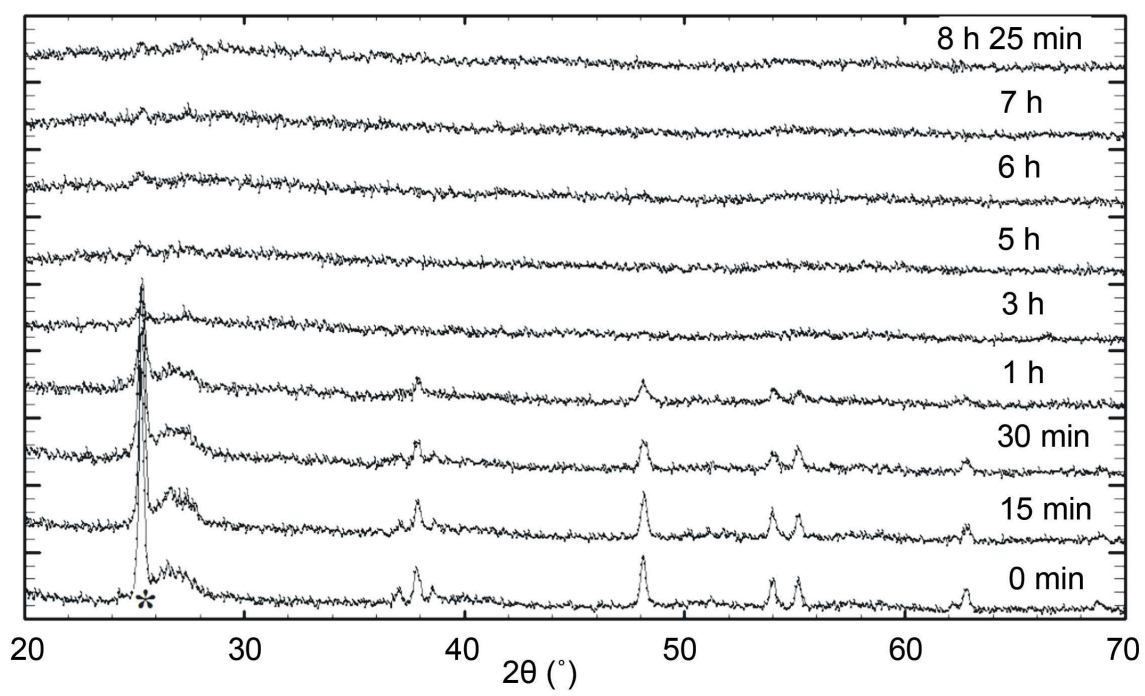

Figure 5. Comparative $\mathrm{X}$-ray patterns of $\mathrm{TiO}_{2}$ samples measured by grinding at different times (15 and $30 \mathrm{~min} ; 1,3,5,6,7$ and $8 \mathrm{~h}$ ).

Table 2. The relationship between grinding time and crystallite size of $\mathrm{TiO}_{2}$ powder.

\begin{tabular}{cccccccc}
\hline $\mathrm{N}$ & Milling time & $\theta_{0}$ & $\cos \theta_{0}$ & $\Delta B\left(2 \theta_{0}\right)$ & $K$ & $\begin{array}{c}\lambda, \mathrm{nm} \\
\left(\mathrm{Cu} / \mathrm{K}_{\alpha}\right)\end{array}$ & $D_{c}, \mathrm{~nm}$ \\
\hline 1 & 0 (unmilled) & 12.640 & 0.9757 & 0.250 & 0.94 & 0.154 & 34.0 \\
2 & $15 \mathrm{~min}$ & 12.690 & 0.9755 & 0.290 & - & - & 29.3 \\
3 & $30 \mathrm{~min}$ & 12.670 & 0.9756 & 0.310 & - & - & 27.4 \\
4 & $1 \mathrm{~h}$ & 12.690 & 0.9755 & 0.300 & - & - & 28.3 \\
5 & $3 \mathrm{~h}$ & 12.670 & 0.9756 & 0.380 & - & - & 22.3 \\
6 & $5 \mathrm{~h}$ & 12.670 & 0.9756 & 0.830 & - & - & 10.2 \\
7 & $6 \mathrm{~h}$ & 12.640 & 0.9757 & 1.030 & - & - & 8.2 \\
8 & $7 \mathrm{~h}$ & 12.660 & 0.9756 & 0.530 & - & - & 16.0 \\
9 & $8 \mathrm{~h} 25 \mathrm{~min}$. & 12.690 & 0.9755 & 0.490 & - & - & 17.3 \\
\hline
\end{tabular}


slightly to $28 \mathrm{~nm}$. The sample was further ground for 6 hours to reduce the crystallite size to $\sim 8 \mathrm{~nm}$. When the sample was ground for 7 hours and 8 hours and 25 minutes, there was a tendency that the crystallite size in the samples increased again. In the work [11], the reason for the increase in particle size was explained by the electrostatic effect of very fine particles.

Investigation of particle size of powdered $\mathrm{TiO}_{2}$ : Photon cross correlation spectroscopy (PCCS with Nanophox) is an instrument that simultaneously makes accurate measurements of particle size and stability of opaque suspensions and emulsions in the range of $1 \mathrm{~nm}$ to $10,000 \mathrm{~nm}$. The powdered $\mathrm{TiO}_{2}$ sample was prepared in the form of suspension samples by immersion in double distilled water, depending on the grinding time. KS 900F ultrasonic generator was used to disperse the suspension for 1 minute. The suspension sample for PCCS measurements was prepared in a $12.5 \mathrm{~mm}$ wide, $12.5 \mathrm{~mm}$ deep, and 36 mm high disposable clear plastic cuvette (Eppendorf UVette@, Sympatec part No. NZ0020) with a filling volume of $50 \mu$ to $2000 \mu$ l. The cuvette was placed in a thermostatically adjusted container of clean water so that it is orthogonal to the beam path of the $632.8 \mathrm{~nm}$ HeNe laser. Then the thermostat was filled with $0.22 \mu \mathrm{m}$ filtered double distilled water to a level of $3 / 4$. Windox 5 software was used to process the measurement results. As an example, Figure 6 shows the density distributions of a $\mathrm{TiO}_{2}$ powder sample. Similar plots as in Figure 6 were also obtained for other milled samples.

The particle size, which is $50 \%$ of the cumulative distribution, indicates the average particle size of the sample. As shown in Figure 6, the average particle size is $221 \mathrm{~nm}$, the range of particle size distribution is $41 \mathrm{~nm}-343 \mathrm{~nm}$, and the specific surface area is $27.35\left(\mathrm{~m}^{2} / \mathrm{cm}^{3}\right)$. The number of nanoparticles $(<100 \mathrm{~nm})$ was $0.04 \%$ by volume. The shape of the density distribution curve is Gaussian symmetric. The particle sizes measured with the PCCS device at different meals were taken from the graphs of experimental results and summarized in Table 3.

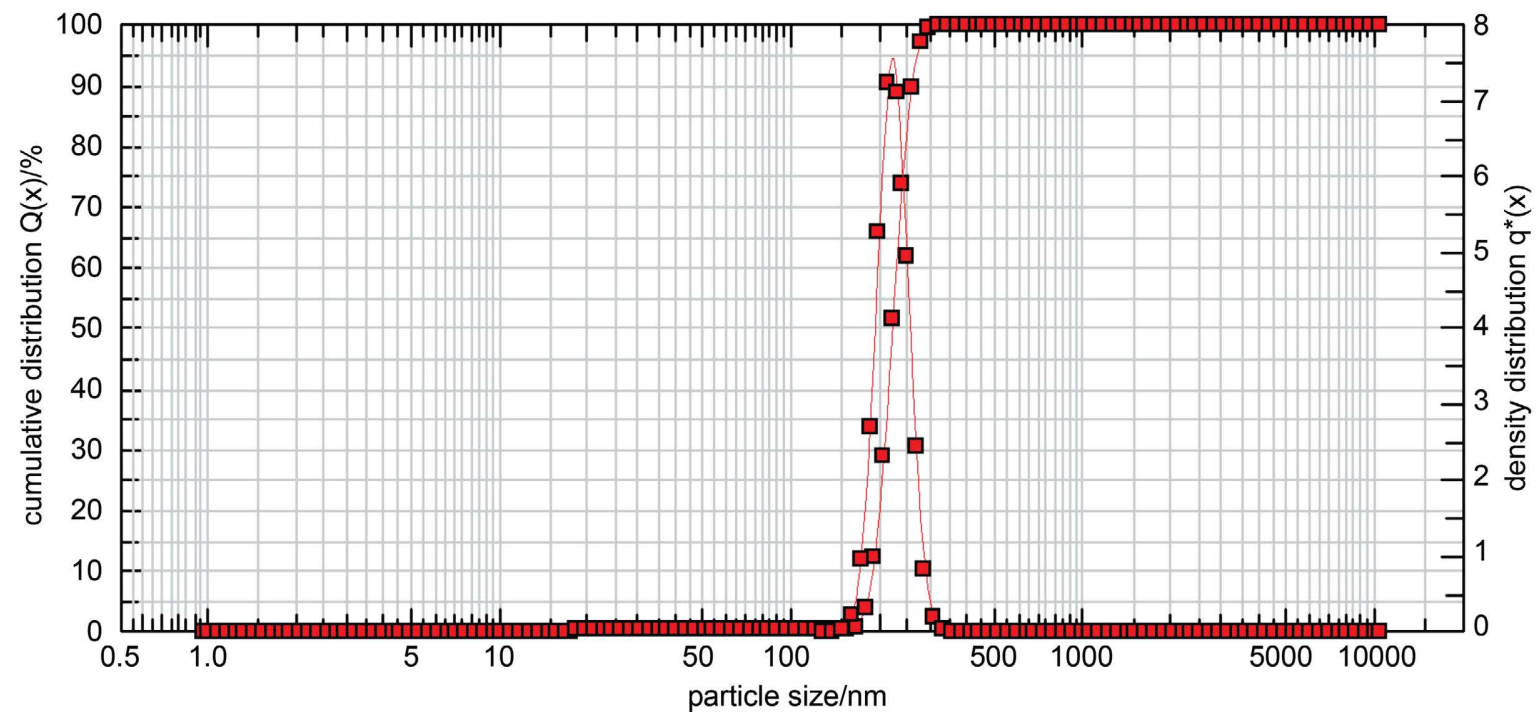

Figure 6. Particle size and cumulative distribution $(\mathrm{Q}(\mathrm{x}))$, particle size and density distribution $\left(\mathrm{q}^{\star}(\mathrm{x})\right)$. 
Table 3. Particle size parameters of $\mathrm{TiO}_{2}$.

\begin{tabular}{ccccc}
\hline $\mathrm{N}$ & $\begin{array}{c}\text { Grinding time } \\
(\mathrm{t})\end{array}$ & $\begin{array}{c}\text { The average } \\
\text { particle size } \\
\left(\bar{x}_{50}\right)\end{array}$ & $\begin{array}{c}\text { Particle size } \\
\text { distribution }\end{array}$ & $\begin{array}{c}\text { Specific surface } \\
\text { area }\left(\mathrm{m}^{2} / \mathrm{cm}^{3}\right)\end{array}$ \\
\hline 1 & 0 (unmilled) & $4.6 \mu \mathrm{m}$ & $133 \mathrm{~nm} \div 7.7 \mu \mathrm{m}$ & 1.30 \\
2 & $15 \mathrm{~min}$ & $429 \mathrm{~nm}$ & $319 \mathrm{~nm} \div 6.5 \mu \mathrm{m}$ & 14.06 \\
3 & $30 \mathrm{~min}$ & $381 \mathrm{~nm}$ & $296 \mathrm{~nm} \div 530 \mathrm{~nm}$ & 15.80 \\
4 & $1 \mathrm{~h}$ & $470 \mathrm{~nm}$ & $368 \mathrm{~nm} \div 659 \mathrm{~nm}$ & 12.81 \\
5 & $3 \mathrm{~h}$ & $280 \mathrm{~nm}$ & $238 \mathrm{~nm} \div 368 \mathrm{~nm}$ & 21.49 \\
6 & $5 \mathrm{~h}$ & $406 \mathrm{~nm}$ & $319 \mathrm{~nm} \div 570 \mathrm{~nm}$ & 14.84 \\
7 & $6 \mathrm{~h}$ & $221 \mathrm{~nm}$ & $41 \mathrm{~nm} \div 343 \mathrm{~nm}$ & 27.35 \\
\hline
\end{tabular}

The surface area to surface volume ratio increases drastically with the decrease of particle size. After the $\mathrm{TiO}_{2}$ sample was ground for 6 hours, the specific surface area increased from 1.30 to $27.35\left(\mathrm{~m}^{2} / \mathrm{cm}^{3}\right)$. This indicates an increase in the chemical activity of the $\mathrm{TiO}_{2}$ powder. The average particle size of the $\mathrm{TiO}_{2}$ sample was reduced from $4.6 \mu \mathrm{m}$ to $221 \mathrm{~nm}$. The lack of PCCS measurements for ground samples up to 7 and 8 hours is due to the inability to prepare water stable suspensions.

\section{Conclusions}

Based on the above analysis, the conclusions were summarized as follows:

1) Short-time grinding and slow cooling can be an effective way to rapidly reduce the crystallite size of powder materials.

2) X-ray diffraction analysis showed that no phase transition was observed in anatase $\mathrm{TiO}_{2}$ as a function of the short grinding time.

3) The crystallite sizes of the anatase $\mathrm{TiO}_{2}$ powder sample were reduced from $34 \mathrm{~nm}$ to $8 \mathrm{~nm}$ as a function of milling time.

4) Photon cross-correlation spectroscopic measurements revealed that the average particle size of a $\mathrm{TiO}_{2}$ particle with $\sim 8 \mathrm{~nm}$ was $221 \mathrm{~nm}$. The number of nanoparticles $(<100 \mathrm{~nm})$ was $0.04 \%$ of the volume.

\section{Acknowledgements}

This work was funded by the basic research project "Study of Thermal Storage Nanomaterials" of Mongolian Science and Technology Foundation. The authors gratefully acknowledge the financial support from Mongolian Science and Technology Foundation.

\section{Conflicts of Interest}

The authors declare no conflicts of interest regarding the publication of this paper. 


\section{References}

[1] Hanaor, D.A.H. and Sorrell., C.C. (2011) Review of the Anatase to Rutile Phase Transformation. Journal of Materials Science, 46, 885-874. https://doi.org/10.1007/s10853-010-5113-0

[2] Ge, M., Cao, C., Huang, J., Shuhui, L. and Chen, Z. (2016) A Review of One-Dimensional $\mathrm{TiO}_{2}$ Nanostructured Materials for Environmental and Energy Applications. Journal of Materials Chemistry A, 4, 6772-6801. https://doi.org/10.1039/C5TA09323F

[3] Theivasanthi, T. (2017) Review on Titania Nanopowder-Processing and Applications. arXiv:1704.00981 [cond-mat.mtrl-sci]

[4] Ohkoshi, S., Tsunobuchi, Y., Matsuda, T., et al. (2010) Synthesis of a Metal Oxide with a Room-Temperature Photoreversible Phase Transition. Nature Chemistry, 2, 539-545. https://doi.org/10.1038/nchem.670

[5] Kumar, G.N. and Reddy, G.B. (2017) Experimental Analysis on Nano-Based Phase Change Material for Cooling Applications in Tropical Buildings. Journal of Science and Technology, 13, 101-116.

[6] Daou, I., El-Kaddadi, L., Zegaoui, O., Asbik, M. and Zari, N. (2017) Structural, Morphological and Thermal Properties of Novel Hybrid-Microencapsulated Phase Change Materials Based on $\mathrm{Fe}_{2} \mathrm{O}_{3}, \mathrm{ZnO}$ and $\mathrm{TiO}_{2}$ Nanoparticles for Latent Heat Thermal Energy Storage Applications. Journal of Energy Storage, 17, 84-92. https://doi.org/10.1016/j.est.2018.02.011

[7] Al-Kayiem, H.H., Lin, S.C. and Lukmon, A. (2013) Review on Nanomaterials for Thermal Energy Storage Technologies. Nanoscience and Nanotechnology-Asia, 3, 60-71. https://doi.org/10.2174/22113525113119990011

[8] Es-Soufi, H. and Bih, L. (2021) Effect of $\mathrm{TiO}_{2}$ on the Chemical Durability and Optical Properties of Mo-Based Phosphate Glasses. Journal of Non-Crystalline Solids, 558, Article ID: 120655. https://doi.org/10.1016/j.jnoncrysol.2021.120655

[9] Es-Soufi, H., Bih, L., Lima, A.R.F., et al. (2021) Investigation DSC and XRD on the Crystallization Kinetics in the Phosphate $\mathrm{Li}_{2} \mathrm{O}-\mathrm{Li}_{2} \mathrm{WO}_{4}-\mathrm{TiO}_{2}-\mathrm{P}_{2} \mathrm{O}_{5}$ Glassy Ionic System. Journal of Materials Science: Materials in Electronics, 32, 101-112. https://doi.org/10.21203/rs.3.rs-190511/v1

[10] Sen, S., Ram, M.L., Roy, S. and Sarkar, B.K. (1999) The Structural Transformation of Anatase $\mathrm{TiO}_{2}$ by High-Energy Vibrational Ball Milling. Journal of Materials Research, 14, 841-848. https://doi.org/10.1557/JMR.1999.0112

[11] Salari, M., Rezaee, M., Mousavi Koie, S.M., Marashi, P. and Aboutalebi, H. (2008) Effect of Milling Time on Mechanochemical Synthesis of $\mathrm{TiO}_{2}$ Nanoparticles. International Journal of Modern Physics B, 22, 2955-2961. https://doi.org/10.1142/S0217979208047808

[12] Roisnel, T. and Rodriguez-Carvajal, J. (2014) FullProf Suite: Winplotr, A Graphic Tool for Powder Diffraction. Version: April 2014. 